\title{
Patterns of sensory and autonomic reinnervation of long-standing myocutaneous microvascular flaps and split-skin grafts applied to fascial beds
}

\author{
A Juma MBBS FRCS FRCS(Plast) ${ }^{1}$, D Oudit MD MRCS ${ }^{2}$, M Ellabban MD MSc FRCS(I) FRCS ${ }^{3}$
}

\begin{abstract}
A Juma, D Oudit, M Ellabban. Patterns of sensory and autonomic reinnervation of long-standing myocutaneous microvascular flaps and split-skin grafts applied to fascial beds. Can J Plast Surg 2005;13(1):16-22.
\end{abstract}

BACKGROUND: There is a paucity of reports in the literature examining the pattern of sensory and autonomic neural recovery of myocutaneous microvascular flaps and skin grafts to the lower limbs after a prolonged period of time.

OBJECTIVES: To investigate the recovery of sensation and autonomic nerve activity in long-standing split-skin grafts applied to fascial beds and in myocutaneous microvascular flaps.

METHODS: The patients were divided into two groups: group A consisted of patients with a split-skin graft applied to a fascial bed $(n=11)$ and group B consisted of patients with free microvascular flaps $(n=4)$. Patients in both groups underwent various clinical subjective and objective tests, including the measurement of electrical resistance and thermal sensory analysis. Laser Doppler flowmetry was used to investigate the blood flow patterns.

RESULTS: Patients in both groups showed significantly reduced sensory modalities. However, the findings of both the electrical resistance and laser Doppler flowmetry were significantly different among the patients in group A compared with controls. In contrast, electrical resistance and laser Doppler flowmetry test results were similar in group B and controls.

CONCLUSIONS: Both split-skin grafts applied to fascial beds and microvascular flaps on the lower limb had poor sensory recovery. However, after 15 years, the microvascular flaps regained the ability to sweat and some degree of thermoregulatory function. This may imply that the long-standing myocutaneous free flaps regained some aspects of their autonomic innervation, whereas the split-skin grafts had not.

Key Words: Autonomic innervation; Flaps; Long-standing; Reinnervation; Sensation; Split-skin grafts

\section{Des motifs de réinnervation sensorielle et neurovégétative de lambeaux microvasculaires myocutanés de longue date et de greffes dermo-épidermiques aponévrotiques}

\begin{abstract}
HISTORIQUE : La documentation scientifique fait état de peu de comptes rendus sur le motif de rétablissement neuronal sensoriel et neurovégétatif de lambeaux microvasculaires myocutanés et de greffes cutanées dans les membres inférieurs après une période prolongée. OBJECTIFS : Étudier le rétablissement de l'activité nerveuse sensorielle et neurovégétative dans des greffes dermo-épidermiques aponévrotiques de longue date et dans des lambeaux microvasculaires myocutanés.

MÉTHODOLOGIE : Les patients ont été séparés en deux groupes : le groupe A se composait de patients ayant une greffe dermo-épidermique aponévrotique $(n=11)$ et le groupe $B$, de patients présentant des lambeaux microvasculaires libres $(n=4)$. Les patients des deux groupes ont subi divers tests cliniques subjectifs et objectifs, y compris une mesure de la résistance électrique et une analyse sensorielle thermique. Une débitmétrie Doppler à laser a permis d'examiner les motifs de débit sanguin. RÉSULTATS : Les patients des deux groupes ont affiché une diminution considérable des modalités sensorielles. Cependant, les observations tant de la résistance électrique que de la débitmétrie Doppler à laser différaient de manière significative entre les patients du groupe $\mathrm{A}$ et ceux du groupe témoin. Par contre, ces résultats étaient similaires entre les patients du groupe B et ceux du groupe témoin.

CONCLUSIONS : Tant les greffes dermo-épidermiques aponévrotiques que les lambeaux microvasculaires des membres inférieurs comportaient une faible récupération sensorielle. Cependant, au bout de quinze ans, les lambeaux microvasculaires avaient recouvré la capacité de sudation et un certain degré de fonction thermorégulatoire. D'après ce phénomène, les lambeaux libres myocutanés de longue date pourraient retrouver certains aspects de leur innervation neurovégétative, contrairement aux greffes dermo-épidermiques.
\end{abstract}

The skin is an organ that has a profound functional signifi1 cance in the protection of the body from injury and in the thermoregulation of the body. In this respect, reinnervation of sensation and autonomic function in split-skin grafts and myocutaneous microvascular flaps is significant.

The patterns of reinnervation of split-skin grafts and microvascular flaps are different. In addition, the degree of sensory recovery to myocutaneous microvascular flaps is variable. The present study outlines a series of clinical tests to delineate the pattern of sensory and autonomic recovery in myocutaneous microvascular flaps and skin grafts applied to fascial beds. The patients were all studied 15 years postoperatively, and the lower leg was the recipient site in all cases.

${ }^{1}$ Countess of Chester NHS Foundation, Chester; ${ }^{2}$ Royal Preston Hospital NHS Trust, Preston; 3 Selly Oak Hospital NHS Trust, Birmingham, United Kingdom

Correspondence: Mr A Juma, Plastic and Reconstructive Surgery Department, The Countess of Chester NHS Foundation Trust, Liverpool Road, Chester CH2 1UL, England. Telephone 01-244-365988, fax 01-224-366277, e-mail BreastAesthetics@aol.com 


\section{METHODS}

The present study consisted of two groups of patients. Group A consisted of 11 patients who had undergone split-skin grafting onto a fascial bed following wider excision for malignant melanomas on the lower leg. The patients ranged in age from 29 to 63 years, with a mean age of 49.7 years. Group B consisted of four patients who had undergone lower limb reconstruction with non-neurotized latissimus dorsi myocutaneous microvascular flaps. The patients were between 23 and 62 years of age, with a mean age of 45.3 years. At the time of the study, all patients were 15 years following the surgical procedure. Because human subjects were used, the study was performed after approval was received from the local ethics committee.

Both groups were subjected to a series of subjective and clinical objective tests in a room with environmentally controlled parameters. Visual bias was eliminated by performing the tests with the patients' eyes closed. The tests involved methods of assessing the various aspects of sensation, sweating and the blood flow characteristics of these longstanding skin grafts and microvascular flaps.

The clinical subjective tests included the following:

- A calibrated Sweet two-point caliper used to measure the static and moving two-point discrimination. This is a test of the density of innervation or reinnervation;

- A Semmes-Weinstein monofilament aesthesiometer (Roylan Ability One, USA) to measure constant touch;

- A $256 \mathrm{~Hz}$ tuning fork to test vibration sense; and

- A standard pin to induce the sensation of pain. This method of testing has been shown to be a reliable and repeatable method (1).

The clinical objective tests included the following:

\section{Sweating}

An electrical ohmmeter was used to determine the electrical resistance between two fixed points on the skin (graft or microvascular flap) $1 \mathrm{~cm}$ apart. This test is a measure of the capacity to sweat. A high electrical resistance is associated with dry skin.

\section{Sensation}

Measurement of thermal sensory thresholds was performed using a computerized thermal sensory analyzer linked to a ceramic watercooled Peltier probe (Medoc, Israel). Thermal sensory analysis was achieved by the performance of three separate tests. These included:

- Cold sensation: the probe temperature was dropped from $32^{\circ} \mathrm{C}$ to a lower temperature. The patient determined the cut-off point on experiencing a cold sensation.

- Warm sensation: the probe temperature was increased from $32^{\circ} \mathrm{C}$ to a higher temperature. The cut-off point was determined as outlined above.

- Thermal sensory limens: the probe temperature started at a baseline temperature of $32^{\circ} \mathrm{C}$ and was randomly changed (either an elevation or drop in temperature).

The sensation of warmth is mediated by the small nonmyelinated $\mathrm{C}$ fibres, whereas the sensation of cold is mediated by $\mathrm{A} \delta$ cold-specific fibres. This method of assessing sensory recovery in split-skin grafts and flaps provides a psychophysical assessment of the $\mathrm{C}$ and $\mathrm{A} \delta$ fibres.

\section{Blood flow}

Laser Doppler flowmetry was used to study the blood flow within the microcirculation of the skin. It measures a relative index of blood flow at a depth of $1 \mathrm{~mm}$ by monitoring dynamic fluctuations within the microcirculation of the skin. This method is useful for comparing blood flow among different subjects or different anatomical sites on the same patient (2). Four separate measurements were performed. The temperature of both thermodes (test and control) was set at a baseline of $32^{\circ} \mathrm{C}$ and a baseline blood flow measurement (T1) was taken for $1 \mathrm{~min}$. The temperature was gradually increased to $42^{\circ} \mathrm{C}$ and the flow of blood was recorded (T2). Two further measurements, $\mathrm{T} 3$ and $\mathrm{T} 4$, were recorded at $1 \mathrm{~min}$ and $3 \mathrm{~min}$, respectively, after heating to $42^{\circ} \mathrm{C}$. The temperature of the thermodes was then dropped to $32^{\circ} \mathrm{C}$ and another recording, $\mathrm{O} 1$, was performed. This was followed by measurements at $1 \mathrm{~min}, 5 \mathrm{~min}$ and $10 \mathrm{~min}(\mathrm{O} 2, \mathrm{O} 3$ and $\mathrm{O} 4$, respectively). At point $\mathrm{O} 4$, the temperature was again increased to $42^{\circ} \mathrm{C}$ and measurements at the time of increasing the temperature, then after $1 \mathrm{~min}$ and $3 \mathrm{~min}$ (R1, R2 and R3, respectively) were recorded (Figure 1).

\section{RESULTS}

In group A (skin grafts applied to fascial beds), the skin grafts showed no recovery of sensory modalities even after 15 years following the procedure. In group B (myocutaneous free latissimus dorsi flaps), the analogue score tests (the static and moving two-point discrimination and the SemmesWeinstein tests) were in keeping with the observation that these flaps also did not recover sensory modalities 15 years following the procedures. In this group, the results of the analogue score tests were significantly different from the controls at $\mathrm{P} \leq 0.05$. Although sensation to vibration (as detected by the $256 \mathrm{~Hz}$ tuning fork test) and pain were improved in the patients in group A compared with those in group B, both groups showed an overall pattern of reduced sensory modalities (Tables 1 and 2).

The results of the Ohms test revealed a high mean electrical resistance that was associated with dry skin in the participants of group A. This finding suggests the absence of sweat gland activity in the tested areas. These results were analyzed using the paired $t$ test, and were found to reflect a statistically significant difference at $\mathrm{P} \leq 0.08$ in the studied areas of the participants in group A compared with the control areas. This was contrary to the findings in the participants of group B, in which the Ohm test showed no significant difference between control and test means $(\mathrm{P}=0.17)$ (Tables 1 and 2$)$. Hence, in this group, there was no significant difference in the degree of sweating on the flaps after 15 years compared with normal skin.

The results of the thermal sensory analysis depicted a similar pattern of behaviour among the participants of group $A$ in all three tests. The mean values were significantly different from the controls in all tests. This reflected a lack of recovery of sensation even 15 years following the procedures. In group B, a similar pattern was noted, with all the tests achieving high peaks reflecting a lack of sensory return (Tables 3 and 4, and Figures 2 and 3 ).

The blood flow patterns using laser Doppler flowmetry demonstrated that there was a significant difference in the baseline blood flow between the test and control samples in group $\mathrm{A}(\mathrm{P} \leq 0.01)$. This finding was consistent with the findings after heating $(\mathrm{P} \leq 0.05)$, cooling $(\mathrm{P} \leq 0.02)$ and reheating 


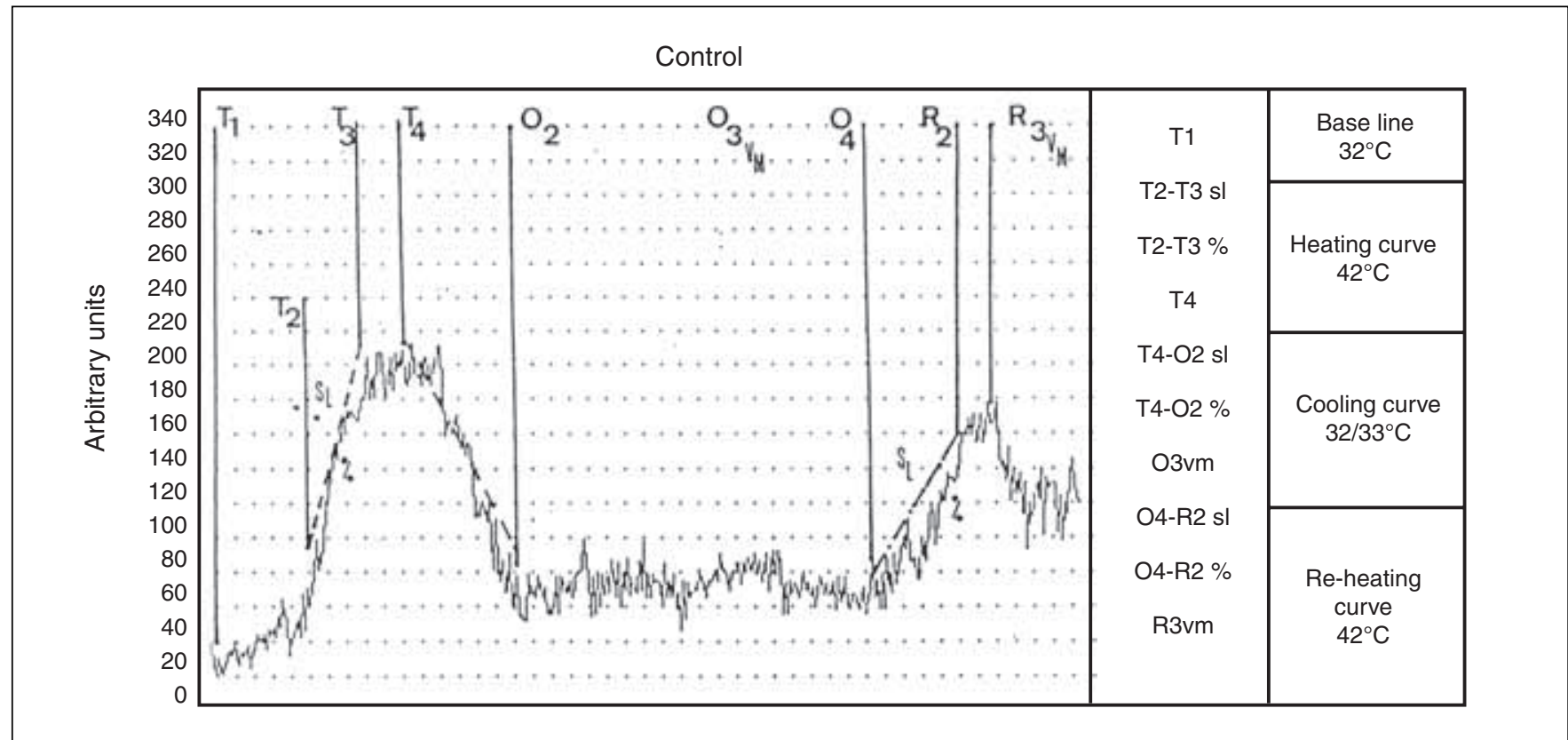

Figure 1) The pattern of blood flow as measured by laser Doppler flowmetry of the skin grafts applied to fascial beds. Note a significant difference in the patterns of blood flow between the test and control sides. O3vm Maximum velocity at the end of cooling; O4-R2 sl Reheating curve gradient; R3vm Reheating curve maximum blood flow at $42^{\circ} \mathrm{C}$; T1 Baseline skin blood flow; T2-T3 sl Heating curve gradient; T4 Maximum blood flow at $42^{\circ} \mathrm{C}$; T4-O2 sl Cooling curve gradient

\section{TABLE 1}

Results of sensory tests for group A

\begin{tabular}{llc}
\hline Tests & Mean $^{*}$ & $\mathbf{P}$ \\
\hline Static two-point discrimination & $38 / 90$ & $<0.001$ \\
Moving two-point discrimination & $34 / 90$ & $<0.001$ \\
Semmes-Weinstein test & $25 / 403$ & $<0.001$ \\
Vibration test $-256 \mathrm{~Hz}$ & $10 / 4.7$ & $<0.001$ \\
Pain & $10 / 0.2$ & $<0.001$ \\
Ohm test & $673 / 1000$ & 0.08
\end{tabular}

*Figures are presented as control/test and are in arbitary units. Level of significance $P \leq 0.05$

TABLE 2

\section{Results of sensory tests for group $B$}

\begin{tabular}{lcc}
\hline Tests & Mean $^{*}$ & $\mathbf{P}$ \\
\hline Static two-point discrimination & $27.5 / 100$ & 0.002 \\
Moving two-point discrimination & $25.2 / 100$ & 0.001 \\
Semmes-Weinstein test & $29.3 / 341$ & 0.05 \\
Vibration test $-256 \mathrm{~Hz}$ & $10 / 0.8$ & $<0.001$ \\
Pain & $10 / 0.3$ & $<0.001$ \\
Ohm test & $29 / 78$ & 0.17 \\
\hline
\end{tabular}

${ }^{*}$ Figures are presented as control/test and are in arbitary units. Level of significance $P \leq 0.05$

$(\mathrm{P} \leq 0.05)$ (Table 5 and Figure 4). However, the blood flow patterns (baseline, heating, cooling and reheating) were not statistically significant between the control and the test groups among the participants of group B (Table 6 and Figure 5). Therefore, the response noted in group B was in keeping with that of normal skin.
TABLE 3

Results of thermal sensory analysis tests for group A

\begin{tabular}{lcc}
\hline Tests & Mean $^{*}$ & $\mathbf{P}$ \\
\hline Cold sensation $\left({ }^{\circ} \mathrm{C}\right)$ & $29.7 / 7.8$ & $<0.001$ \\
Warm sensation $\left({ }^{\circ} \mathrm{C}\right)$ & $35.9 / 46.6$ & $<0.001$ \\
Thermal sensory limens $\left({ }^{\circ} \mathrm{C}\right)$ & $5.8 / 36.9$ & $<0.001$ \\
\hline
\end{tabular}

${ }^{*}$ Figures are presented as control/test. Level of significance $P \leq 0.05$

TABLE 4

Results of thermal sensory analysis tests for group B

\begin{tabular}{lcl}
\hline Tests & Mean $^{*}$ & $\mathbf{P}$ \\
\hline Cold sensation $\left({ }^{\circ} \mathrm{C}\right)$ & $28.7 / 2.0$ & 0.001 \\
Warm sensation $\left({ }^{\circ} \mathrm{C}\right)$ & $36.2 / 47.5$ & 0.002 \\
Thermal sensory limens $\left({ }^{\circ} \mathrm{C}\right)$ & $6.2 / 41$ & 0.01
\end{tabular}

${ }^{*}$ Figures are presented as control/test. Level of significance $P \leq 0.05$

\section{DISCUSSION}

Coverage of lower limb soft tissue defects is a common task undertaken in reconstructive surgery, and there are many methods of achieving this. However, soft tissue coverage is commonly achieved either by a skin graft on a healthy muscle or fascial bed, or by the use of a microvascular myocutaneous flap. The choice of method depends on the clinical circumstances surrounding the individual case. Despite this being a relatively common practice, there is a paucity of reports in the literature examining the sensation of myocutaneous microvascular flaps and skin grafts to the lower limbs and the pattern of sensory recovery, or lack thereof, after a prolonged period. Studies on the autonomic innervation and functions of microvascular flaps have also been scarce.

In the present study, the sensory and autonomic functions (as represented by tests of sweating and the blood flow characteristics 


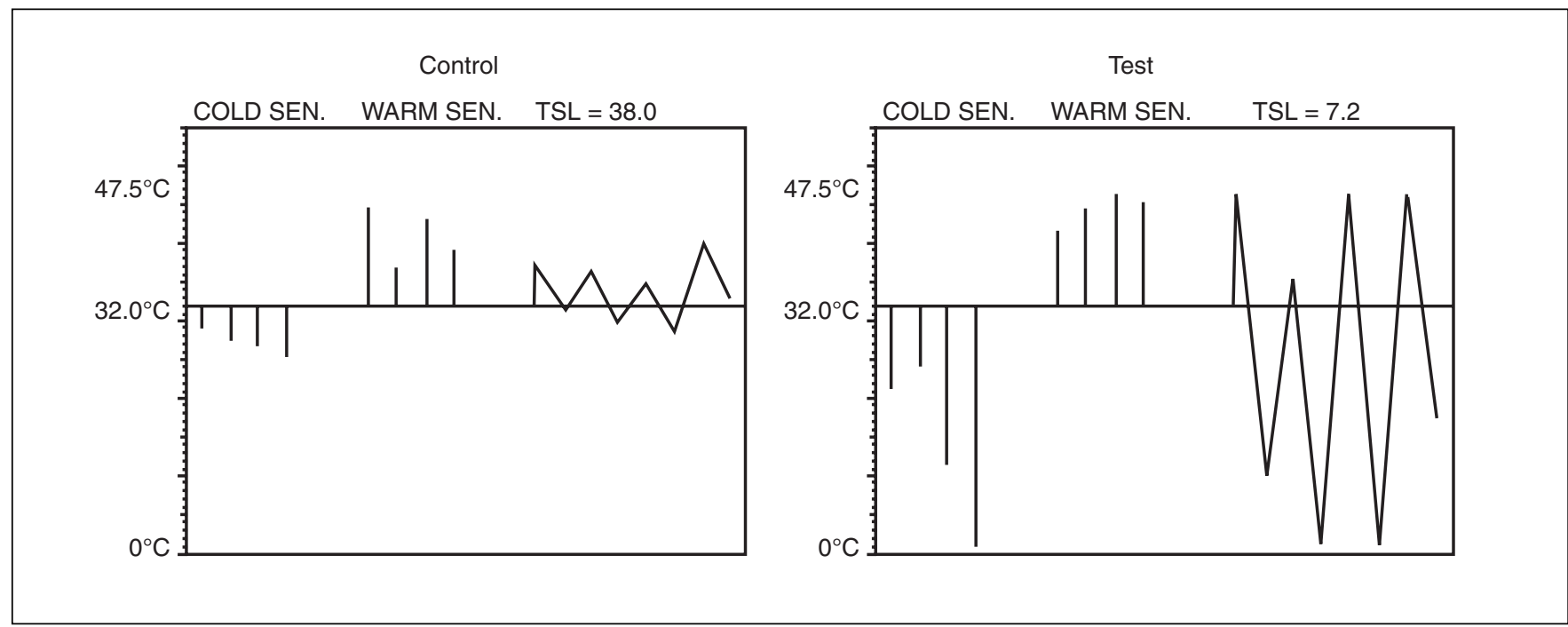

Figure 2) A graphical representation of the results of the thermal sensory analysis test for patients in group A (control and test). SEN Sensation; TSL Thermal sensory limens
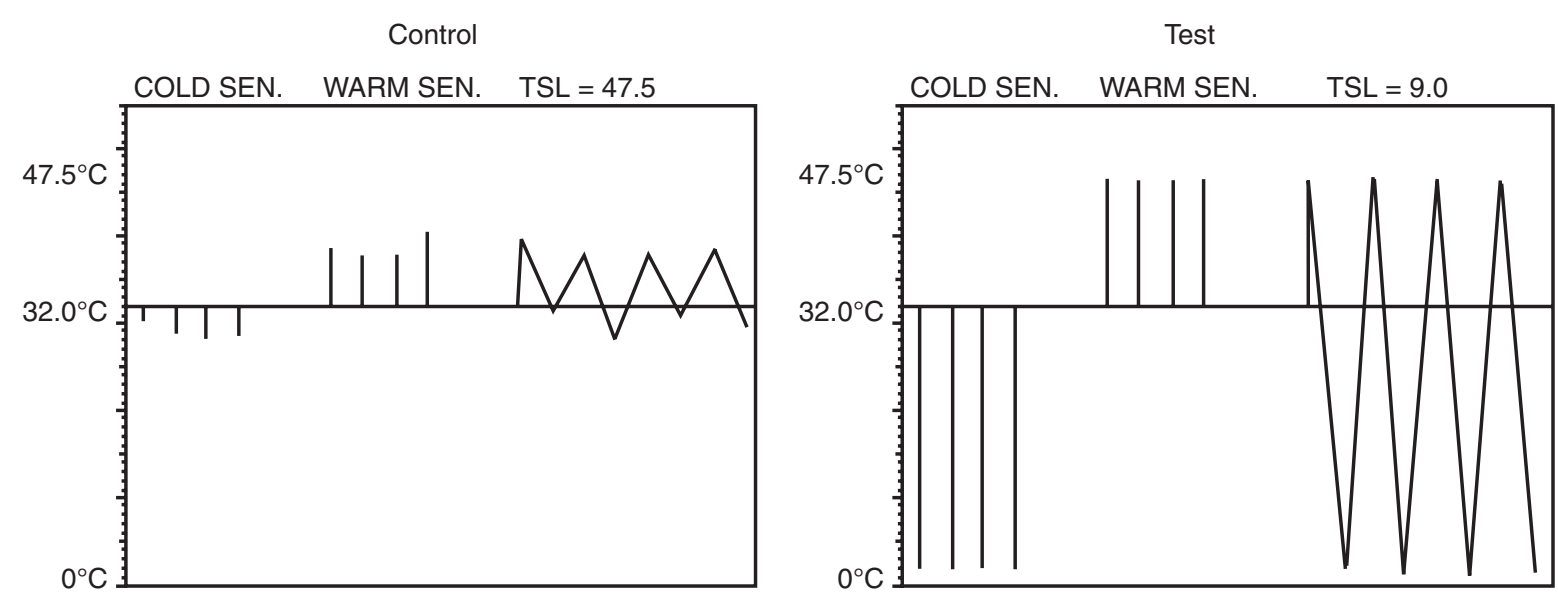

Figure 3) A graphical representation of the results of the thermal sensory analysis test for patients in group B (control and test). SEN Sensation; TSL Thermal sensory limens

at different temperatures) of myocutaneous microvascular flaps to the lower limbs were examined and the findings were compared with those of split-skin grafts applied to fascial beds. Both the microvascular flaps and the skin grafts were examined 15 years after their inset.

Reinnervation and sensory recovery of skin grafts and flaps are important in protecting these tissues from injury. It has been reported that the recovery of sensory innervation postoperatively is earlier with flaps than with grafts (3). On the other hand, it has also been found that skin grafts over reinnervated free muscle flaps can develop significantly better innervation than skin grafts over noninnervated muscle flaps (4). Furthermore, Hattori et al (5) pointed out that within the flap, if the muscle surface was intact, sensory reinnervation of the grafted skin was poor. They found that sensory nerves regenerated, penetrated into the muscle and grew into the overlying grafted skin if the muscle surface was trimmed.

The recovery of sensation in microvascular free flaps is somewhat more variable and depends on whether the flaps
TABLE 5

Results of laser Doppler flowmetry for group A

\begin{tabular}{llcc}
\hline Tests & & Mean $^{*}$ & $\mathbf{P}$ \\
\hline T1 & Baseline skin blood flow & $10.9 / 5.4$ & 0.1 \\
T2-T3 sl & Heating curve gradient & $1.0 / 0.1$ & $<0.001$ \\
T4 & Max blood flow at $42^{\circ} \mathrm{C}$ & $111 / 28$ & $<0.001$ \\
T4-O2 sl & Cooling curve gradient & $0.6 / 0.003$ & 0.001 \\
O3vm & Max velocity at the end of cooling & $46 / 21$ & 0.02 \\
O4-R2 sl & Reheating curve gradient & $0.4 / 0.05$ & 0.001 \\
R3vm & Reheating curve max blood flow at 42 ${ }^{\circ} \mathrm{C}$ & $100 / 28$ & 0.006 \\
\hline
\end{tabular}

${ }^{*}$ Figures are presented as control/test and are in arbitary units. Level of significance $P \leq 0.05$. Max Maximum

are neurotized (6-8), the site of the recipient bed (5) and the time period following the procedure (6). Also, there is evidence to suggest that there may be heterogeneity in the pattern of sensory recovery in those flaps that regain sensation. 


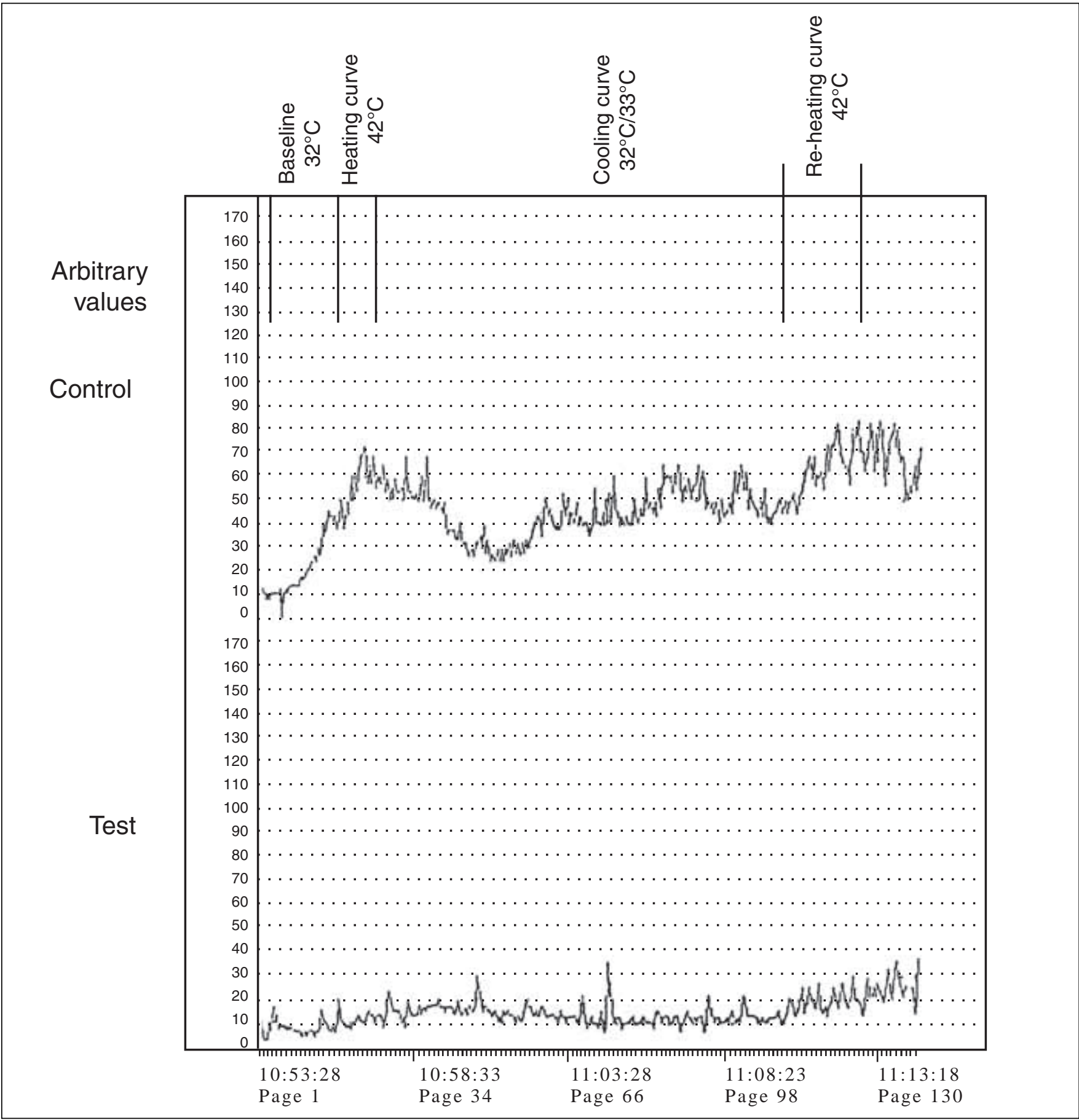

Figure 4) The various stages of the laser Doppler flowmetry test

TABLE 6

Results of laser Doppler flowmetry for group B

\begin{tabular}{llcl}
\hline Tests & & Mean $^{*}$ & $\mathbf{P}$ \\
\hline T1 & Baseline skin blood flow & $33.4 / 6.9$ & 0.13 \\
T2-T3 sl & Heating curve gradient & $0.5 / 0.5$ & 0.81 \\
T4 & Max blood flow at $42^{\circ} \mathrm{C}$ & $97 / 71$ & 0.26 \\
T4-O2 sl & Cooling curve gradient & $0.5 / 0.4$ & 0.93 \\
O3vm & Max velocity at the end of cooling & $46.5 / 46.4$ & 0.99 \\
O4-R2 sl & Reheating curve gradient & $0.4 / 0.2$ & 0.29 \\
R3vm & Reheating curve max blood flow at $42^{\circ} \mathrm{C}$ & $69 / 81$ & 0.5 \\
\hline
\end{tabular}

${ }^{*}$ Figures are presented as control/test and are in arbitary units. Level of significance $P \leq 0.05$. Max Maximum
Santenelli et al (7) found that neurotized fasciocutaneous flaps regained protective sensation after one year but not two-point discrimination or dermatomal somatosensory evoked potential.

Sensory recovery to skin grafts follows a random pattern of reinnervation in which perception of pain returns first, followed by the sense of touch and then temperature. Skin grafts regain their sensory innervation from the graft bed by the regeneration of nerve endings; the exact mechanism is, however, unclear (4).

Sensory recovery in myocutaneous microvascular flaps follows a different pattern. Nerve regeneration begins from the 


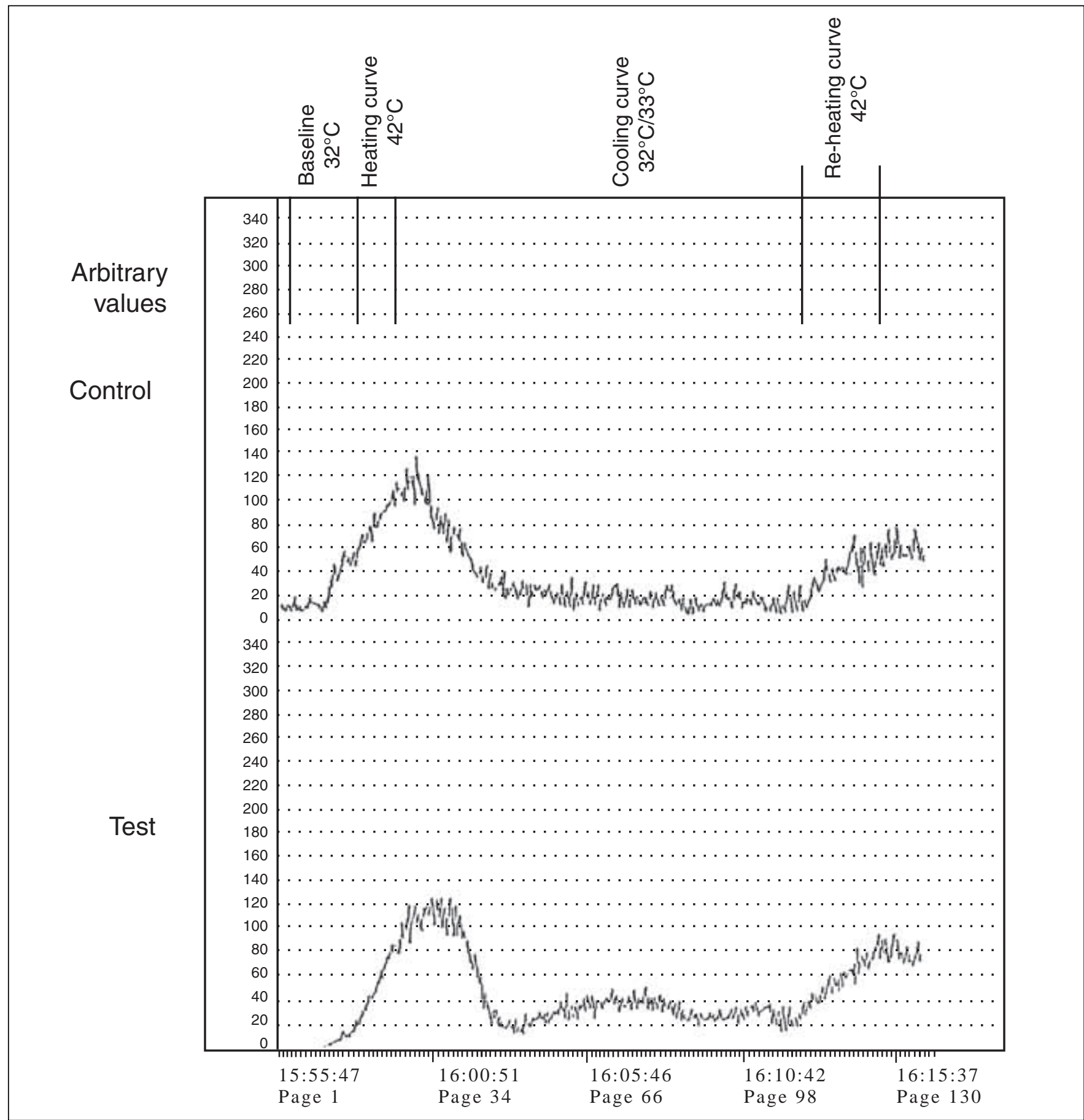

Figure 5) The pattern of blood flow as measured by laser Doppler flowmetry of the myocutaneous microvascular flap. Note the similar pattern of the blood flow between the test and control sides

skin surrounding the wound edge, or from the pedicle (9). Sprouting axons from the flap margins locate empty neurilemmal sheaths as conduits during regeneration (10). Sensory return appears to occur mainly from the margins of the flaps and, to a lesser degree, from the bed (10).

In our study, the sensory recovery of myocutaneous microvascular flaps and split-skin grafts applied to fascial beds was poor even 15 years following surgery. The microvascular flaps studied were all non-neurotized and located on the lower limbs. The location of the recipient site of the flap has been reported to have an impact on the recovery of sensation $(5,11)$. Improved sensory recovery in flaps to the hands, feet and head compared with those of the lower limb has previously been reported $(5,11)$. It is interesting to note that the skin grafts applied to fascial beds on the leg also behaved in a similar manner. Therefore, even after 15 years, the sensory recovery to the myocutaneous microvascular latissimus dorsi flaps and split skin grafts to the leg was poor. On the other hand, cases of sensory recovery in noninnervated microvascular flaps in other parts of the body have previously been reported (12). 
The control of the microcirculation of the skin depends largely on neurogenic influences and skin vasomotor reflexes mediated by the autonomic nervous system. In the present study, flow in the microcirculation was investigated with the use of laser Doppler flowmetry (13). Soderstrom et al (14) has recently used laser Doppler flowmetry to show that sympathetic nerve activity influences blood flow oscillations. Therefore, laser Doppler flowmetry is a useful test of autonomic nerve activity.

Although the split-thickness skin grafts used in group A were of an unknown and potentially variable thickness, it is unlikely that the thickness of the grafts were less than $1 \mathrm{~mm}$ (the depth of penetration of the laser beam).

The autonomic innervation has a direct influence on the blood flow within the microcirculation. The subjecting of skin grafts to changes in temperature (heating and cooling followed by reheating) revealed that they were slower to respond by concomitant changes in the blood flow patterns as demonstrated by laser Doppler flowmetry. This finding may be attributed to a deficit of autonomic nerve activity in these skin grafts. On the other hand, the microvascular flaps behaved in a similar manner to the 'normal skin' when subjected to these tests. This may indicate that after 15 years, although the microvascular flaps had a poor response to sensory recovery, they seem to have some autonomic nerve regeneration and activity.

This finding is reinforced by the observation that the microvascular flaps in the present study produced sweat; in contrast, the skin grafts did not regain this function. The splitthickness skin grafts in group A may have lost some of the sweat glands at the time of harvest. Hence, a lack of sweating noted in skin grafts in the early postoperative period may be attributed to this; however, the grafts examined in this study were all 15 years following the original procedures. It was expected that these long-standing, fully healed skin grafts would have regenerated their appendageal structures by then.

Terenghi (9) reported that the regeneration of the autonomic innervation appeared to be preceded by that of the sensory nerves, based on histological studies on flaps. Our findings of the myocutaneous microvascular flaps revealed that the sensory recovery was poor even after 15 years; however, the flaps appeared to have recovered their autonomic innervation. Although sensory reinnervation may precede autonomic reinnervation, the former may be more variable. This also raises the question of how soon after inset the sensory and autonomic reinnervation occurs.

Therefore, after 15 years, poor sensory recovery was noted in skin grafts to fascial beds and microvascular flaps to the lower leg.
However, the findings in the present study indicate that the microvascular flaps recovered their autonomic nervous function, whereas the skin grafts placed onto fascial beds had not.

This is an initial pilot study. The findings within group B appeared to be consistent. Therefore, with the advice of a statistician, they were subjected to statistical analysis using a paired $t$ test, even though the sample size was small $(n=4)$.

In summary, noninnervated microvascular flaps and splitskin grafts placed on the lower limb as the recipient site have a poor recovery of sensation. However, in long-standing cases, the microvascular flaps appear to recover autonomic functions, whereas the split-skin grafts do not.

\section{REFERENCES}

1. Juma A. Sensory recovery in a split skin graft: Pinprick or a thermal sensory analyzer? Plast Reconstr Surg 2002;109:562-5.

2. Parkhouse N, Le Quesne PM. Quantitative objective assessment of peripheral nociceptive C fibre function. J Neurol Neurosurg Psychiatry 1988;51:28-34.

3. Lutz ME, Otley CC, Roenigk RK, Brodland DG, Li H. Reinnervation of flaps and grafts of the face. Arch Dermatol 1998;134:1271-4.

4. Bayramicli M, Jackson IT, Herschman B. Innervation of skin grafts over free muscle flaps. Br J Plast Surg 2000;53:130-6.

5. Hattori Y, Chuang DC, Lan CT. Sensory restoration of the skin graft on a free muscle flap: Experimental rabbit study. Plast Reconstr Surg 2001;108:132-40.

6. Siemionow M, Latifoglu O, Demirkan F, Siemionow W, Lister G. Assessment of muscle flap sensibility by evoked potentials in the rat. Microsurgery 2000;20:85-93.

7. Santenelli F, Tenna S, Pace A, Scuderi N. Free flap reconstruction of the sole of the foot with or without sensory nerve coaptation. Plast Reconstr Surg 2002;109:2314-24.

8. Hermanson A, Dalsgaard CJ, Bjorklund H, Lindblom U. Sensory reinnervation and sensibility after superficial skin wounds in human patients. Neurosci Lett 1987;74:377-82.

9. Terenghi G. Peripheral nerve injury and regeneration. Histol Histopathol 1995;10:709-18.

10. Turkof E, Jurecka W, Sikos G, Piza-Katzer H. Sensory recovery in myocutaneous, noninnervated free flaps: A morphologic, immunohistochemical, and electron microscopic study. Plast Reconstr Surg 1993;92:238-47.

11. Lahteenmaki T, Waris T, Asko-Seljavaara S, Astrand K, Sundell B, Jarvilehto $T$. The return of sensitivity to cold, warmth and pain from excessive heat in free microvascular flaps. Scand J Plast Reconstr Surg Hand Surg 1991;25:143-50.

12. Liew S, Hunt J, Pennington D. Sensory recovery following free TRAM flap breast reconstruction. Br J Plast Surg 1996;49:210-3.

13. Fagrell B. Dynamics in skin microcirculation in humans. J Cardiovasc Pharmacol 1985;7(Suppl 3):S53-8.

14. Soderstrom T, Stefanovska A, Veber M, Svensson H. Involvement of sympathetic nerve activity in skin blood flow oscillations in humans. Am J Physiol Heart Circ Physiol 2003;284:H1638-46. 